\title{
Interaction between Dietary Vitamin A and Single Oral Doses of 2,3,7,8-Tetrachlorodibenzo-p-Dioxin (TCDD) on the TCDD-Induced Toxicity and on the Vitamin A Status in the Rat ${ }^{1}$
}

\author{
Helen HÅKansSON, Ellu MANZOOR, \\ and Ulf G. AHLBORG \\ The Institute of Environmental Medicine, Karolinska Institutet, \\ Box 60 208, S-104 01 Stockholm, Sweden
}

(Received September 6, 1990)

\begin{abstract}
Summary The effect of dietary vitamin A on the toxicity of $2,3,7,8$ tetrachlorodibenzo-p-dioxin (TCDD) and the effect of TCDD on the tissue vitamin A levels in 8-week-old male Sprague-Dawley rats of variable vitamin A status, were investigated. Rats were fed purified casein based diets containing $2,000,5,000,8,000$, or $21,000 \mathrm{IU}$ of vitamin $\mathrm{A} / \mathrm{kg}$ from weaning and throughout the experiment. The study was terminated 44 days after the administration of a single oral dose of $0,15,30,60$, or $120 \mu \mathrm{g}$ TCDD $/ \mathrm{kg}$ body wt. With this dietary regimen it was possible to obtain healthy animals of the same age with a vitamin A status that varied within a physiological range. $L_{50}$-values for TCDD could not be calculated in any dietary group due to the unexpectedly low mortality rate. The obtained data, however, suggest that low dietary intake of vitamin A impairs the ability to tolerate the lethal effect of TCDD and/or decreases the survival time. Some TCDD-related effects, i.e. body weight loss, liver enlargement and decreased testes weight, were more pronounced in the groups receiving low levels of dietary vitamin A, whereas the decrease in thymus weight was as severe in all dietary groups. Exposure to TCDD had a pronounced effect on tissue vitamin A contents. The effect differed between tissues and was dependent upon the dose of TCDD and on the vitamin A status of the animal. Generally, exposure to TCDD results in the reduction of vitamin A in most organs; very likely because the capacity for vitamin A storage is diminished. The kidney is an exception because it accumulates vitamin A in response either to TCDD itself or to the altered vitamin A status which TCDD induces. Data presented in this study are not sufficient to conclude if the observed
\end{abstract}

1 Supported by grants from the National Swedish Environment Protection Board (5311235-5), the Swedish Work Environment Fund (84-0139), The Ekhaga Foundation, and by funds at the Karolinska Institute. 
changes of tissue vitamin A contents are sufficient to explain the spectrum of morphological changes, which is typical of TCDD exposure.

Key Words 2,3,7,8-tetrachlorodibenzo-p-dioxin, TCDD, vitamin A, diets

The 2,3,7,8-tetrachlorodibenzo-p-dioxin (TCDD), on a molecular basis known to be the most toxic congener among the dibenzo- $p$-dioxins and dibenzofurans, interferes with the vitamin A turnover in the rat (1-10) and other species (11-13). These data suggest that TCDD interacts with the highly regulated but yet not fully understood process of vitamin A storage (14-16). Similarities of TCDD-induced symptoms and effects of dietary vitamin A deficiency in experimental animals are extensive, particularly as regards effects on growth regulation (17-19), cellular differentiation and proliferation $(17,20)$, maintenance of epithelial tissues $(17,20)$, and reproduction $(17,21,22)$. The similarities include both the time-course for effect to occur and the quality of effect.

The present study was undertaken in order to investigate if dietary vitamin A would affect the toxicity of TCDD in the rat and if TCDD would affect the vitamin A homeostasis differently in animals with different vitamin A status.

\section{MATERIALS AND METHODS}

Animals and experimental design. Male Sprague-Dawley rats (ALAB, Sollentuna, Sweden) in experimental groups of five TCDD-treated and four control animals, were fed purified casein based diets ${ }^{2}$ stated to contain 2,000 (diet 1), 5,000 (diet 2), 8,000 (diet 3), or 21,000 (diet 4) IU of vitamin $\mathrm{A} / \mathrm{kg}$ diet (Ewos AB, Södertälje, Sweden). Diets were stored at $-20^{\circ} \mathrm{C}$ throughout the experiment. To obtain animals of the same age with variable vitamin $A$ status at the time of TCDD-administration, feeding of experimental diets started immediately after weaning and continued throughout the study. After 5 weeks on the dietary regimens, experimental animals were given a single oral dose of $0,15,30,60$, or 120 $\mu \mathrm{g}$ TCDD/kg body wt. Two control rats from each dietary group were decapitated

2 The raw materials were: Casein, corn starch, glucose, cellulose fiber, animal and vegetable fat, minerals, vitamin concentrate, and trace element concentrate. The composition was: $20 \%$ protein; 7\% fat; $64 \%$ carbohydrate (corn starch: $44 \%$, glucose: 20\%); 4\% fiber; $6 \%$ moisture. Vitamins per $\mathrm{g}$ diet were: vitamin A: retinylpalmitate as stated in the text; $\beta$-carotene; $0.1 \mu \mathrm{g}$; vitamin D: $1.5 \mathrm{IU}$; vitamin $\mathrm{E}: 42 \mu \mathrm{g}$; menadione: $1.5 \mu \mathrm{g}$; cholinechloride: $1 \mathrm{mg}$; thiamine: $4 \mu \mathrm{g}$; riboflavine: $12 \mu \mathrm{g}$; pyridoxine: $5 \mu \mathrm{g}$; vitamin B12: $40 \mathrm{ng}$; niacin: $40 \mu \mathrm{g}$; pantotheneate: $10 \mu \mathrm{g}$. The minerals were: calcium: $0.6 \%$; phosphorus: $0.3 \%$; sodium: $0.3 \%$; chloride: $0.5 \%$; potassium: $0.5 \%$; magnesium: $0.04 \%$; iron: $292 \mathrm{mg} / \mathrm{kg}$; manganese: $68 \mathrm{mg} / \mathrm{kg}$; zinc: $7 \mathrm{mg} / \mathrm{kg}$; copper $10 \mathrm{mg} / \mathrm{kg}$; iodine: $2 \mathrm{mg} / \mathrm{kg}$; cobalt: $0.4 \mathrm{mg} / \mathrm{kg}$; selenium $100 \mu \mathrm{g} / \mathrm{kg}$. 
to provide data for tissue weights and vitamin A levels at the time of treatment. Animals were housed in wire bottomed plastic cages $(350 \times 250 \times 180 \mathrm{~mm})$. Illumination cycle, $12 \mathrm{~h}$ light and $12 \mathrm{~h}$ dark, was automatically controlled. Food and water were supplied ad libitum. Food consumption was not recorded. TCDDtreated animals were kept in a separate room in order to avoid any contamination of control animals and the surrounding laboratory. Body weights were recorded twice weekly. The surviving rats were killed by blood withdrawal under anesthesia ( $0.4 \mathrm{mg}$ chloral hydrate in saline $/ \mathrm{kg}$ body wt, i.p.) 44 days after treatment. Blood was centrifuged at $1,000 \times g$ and the collected serum was stored at $-70^{\circ} \mathrm{C}$. Tissues, i.e., liver, intestine, kidneys, testes, brain, lung, epididymis, thymus, spleen, and adrenals, were rapidly removed, rinsed in ice-cold saline and blotted with filter paper before weighing. Tissues were stored at $-70^{\circ} \mathrm{C}$ until analyses were performed.

Chemicals. $\quad$ TCDD $^{3}$ for administration $(15,30,60,120 \mu \mathrm{g} / \mathrm{ml}$ arachis oil) was prepared as previously described (3). All other chemicals were of analytical grade and commercially obtained.

Tissue extraction and vitamin $A$ analysis. Completely hydrolyzed and extracted tissue vitamin A was analyzed as previously described (6).

Data analysis. Data reported are the arithmetic means for individual groups. Summary statistical analysis were performed by one- and two-way analysis of variance (ANOVA) using the SPSS/PC $+{ }^{\mathrm{TM}}$ statistical package (SPSS Inc.). The factor for pre-treatment data was diet. Classifiers for post-treatment data were dose and diet. One-way ANOVA and the Tukey-Kramer method for multiple comparisons (23) were used in order to identify significant differences among individual group means within each dietary group. Comparisons were considered significant at the $p<0.05$ level. Data from animals that died prior to the termination of the study were excluded from the statistical analysis. Data from these animals are given as the arithmetic means \pm standard deviation.

Safety precautions for the work with TCDD were as previously described (3).

\section{RESULTS}

\section{Pre-treatment data}

At the time of TCDD-treatment, i.e., after 5 weeks on the four different dietary regimens, tissues of two animals from each dietary group were analyzed to provide the base-line data on tissue weights and vitamin A contents. The different diets had no significant effects on body weight gain or on absolute and relative tissue weights (data not shown). There was a significant effect of diet on the vitamin A content in the liver, intestine, thymus, and adrenals (Tables 1 and 2). Less vitamin A seemed to be present in the testes, lung, spleen, and epididymis of animals in dietary

${ }^{3}$ Lot no 351: 144-II, a generous gift from Dow Chemical Company, Midland, Michigan, U.S.A. 
H. HÅKANSSON et al.
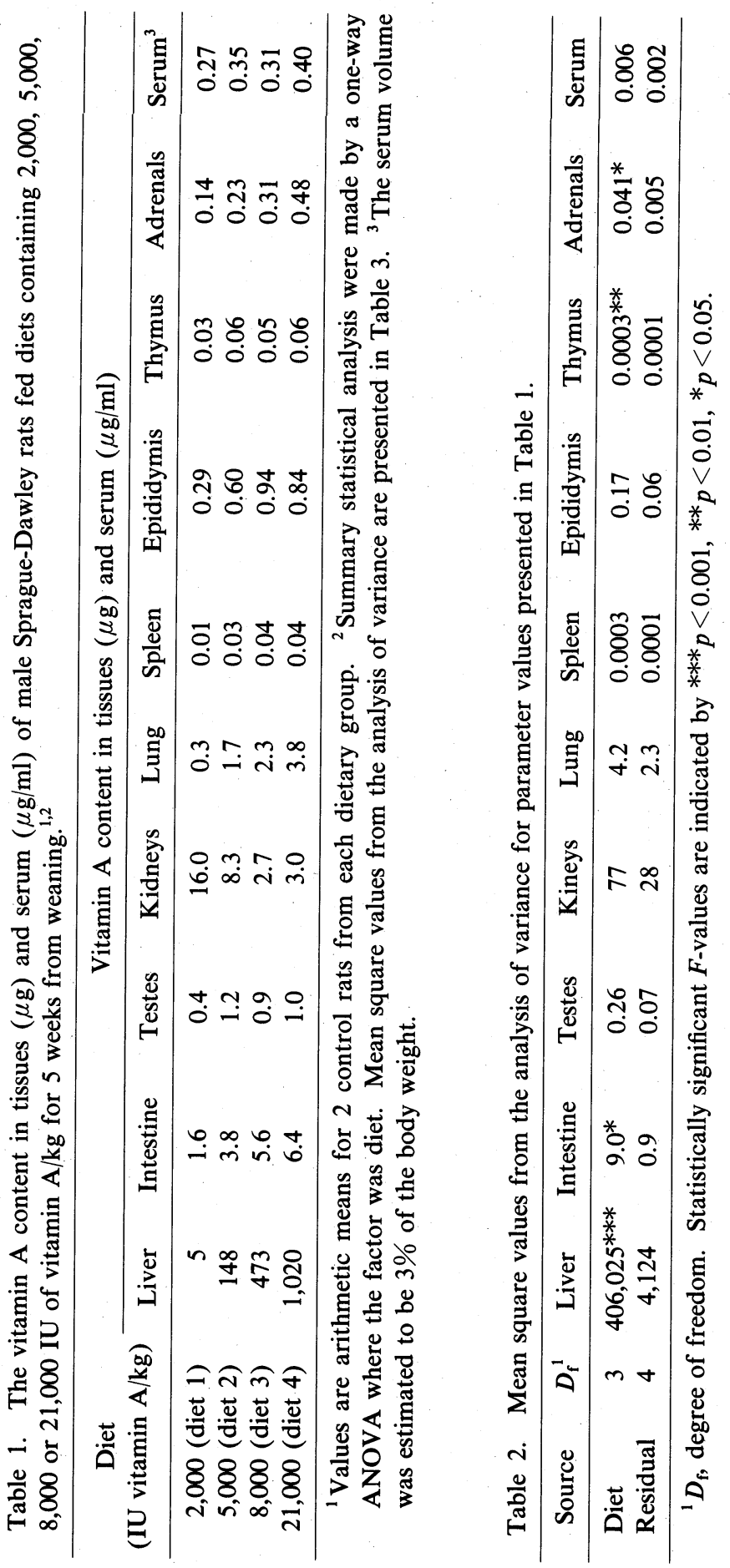

J. Nutr. Sci Vitaminol. 
group 1 as compared to animals in dietary groups 2,3 , and 4, while renal vitamin A, in contrast, was comparatively high in dietary groups 1 and 2 (Table 1). However, none of these differences were statistically significant (Table 2).

\section{Post-treatment data}

Non-surviving animals. Five animals in the group, which received diet 1 , died from TCDD exposure; one at the $30 \mu \mathrm{g} / \mathrm{kg}$ body wt dose level by day 37 after treatment and four at $120 \mu \mathrm{g} / \mathrm{kg}$ body wt after 32 to 41 days. One animal at the highest dose, fed diet 2 , died on day 31 .

The mean body weight at autopsy for animals that died was $185 \pm 32 \mathrm{~g}$; corresponding to a body weight loss of $97 \pm 33 \mathrm{~g}$ or $34 \pm 11 \%$ of the body weight at the time of TCDD-treatment. The hepatic and intestinal vitamin A content was comparable in all animals that died, i.e., about $2 \mu \mathrm{g}$ in both tissues. In dietary group 2 testes, kidneys, lung, eipdidymis, and adrenals contained $0.2,1.4,0.2,0.9$, and 0.3 $\mu \mathrm{g}$, respectively, whereas in dietary group 1 vitamin A was at or below the limit of detection in these tissues.

Surviving animals. Terminal body weight and body weight gain were comparable for control rats on the different diets (Table 3). For both parameters there was a pronounced TCDD-related decrease in all dietary groups (Tables 3 and 4). Animals, which received $120 \mu \mathrm{g}$ TCDD/kg body wt, even lost weight as compared to the weight at the time of treatment (Tables 1 and 3 ). The loss of body weight was most pronounced in animals fed diets marginal (diet 2) or insufficient (diet 1) of vitamin A (Table 3). All organ weights except for the spleen were significantly affected by TCDD-treatment, while dietary vitamin A supplementation was without effect in all tissues but the intestine and adrenals (Table 4). In addition, a significant interaction between treatment and diet was found for several tissues (Table 4). Some TCDD-related effects i.e., body weight loss, liver enlargement, and decreased testes weight, were more pronounced in the groups receiving low levels of dietary vitamin $\mathrm{A}$, whereas the decrease in thymus weight was as severe in all dietary groups.

The vitamin A content of all tissues was significantly affected both by dose and diet (Tables 5 and 6). The two classifiers showed significant interaction for the vitamin A content in all tissues except for thymus (Table 6). Animals fed diet 1 had almost depleted liver stores of vitamin $\mathrm{A}$, which could not be further reduced in response to TCDD-treatment (Table 5). In dietary group 2 there was an almost complete depletion of liver vitamin A already with the $15 \mu \mathrm{g} / \mathrm{kg}$ body wt dose of TCDD, while $30 \mu \mathrm{g}$ TCDD $/ \mathrm{kg}$ body wt was needed for a comparable depletion in animals fed diet 3 (Table 5). The remaining vitamin $A$ in the liver of animals fed diet 3 could not be depleted by the two higher doses of TCDD. Only in dietary group 4 was the TCDD-related hepatic vitamin A reduction linear over the whole dose-range (Table 5).

The intestinal vitamin A content of control animals was similar in all dietary groups (Table 5). Treatment with TCDD decreased the intestinal vitamin A 


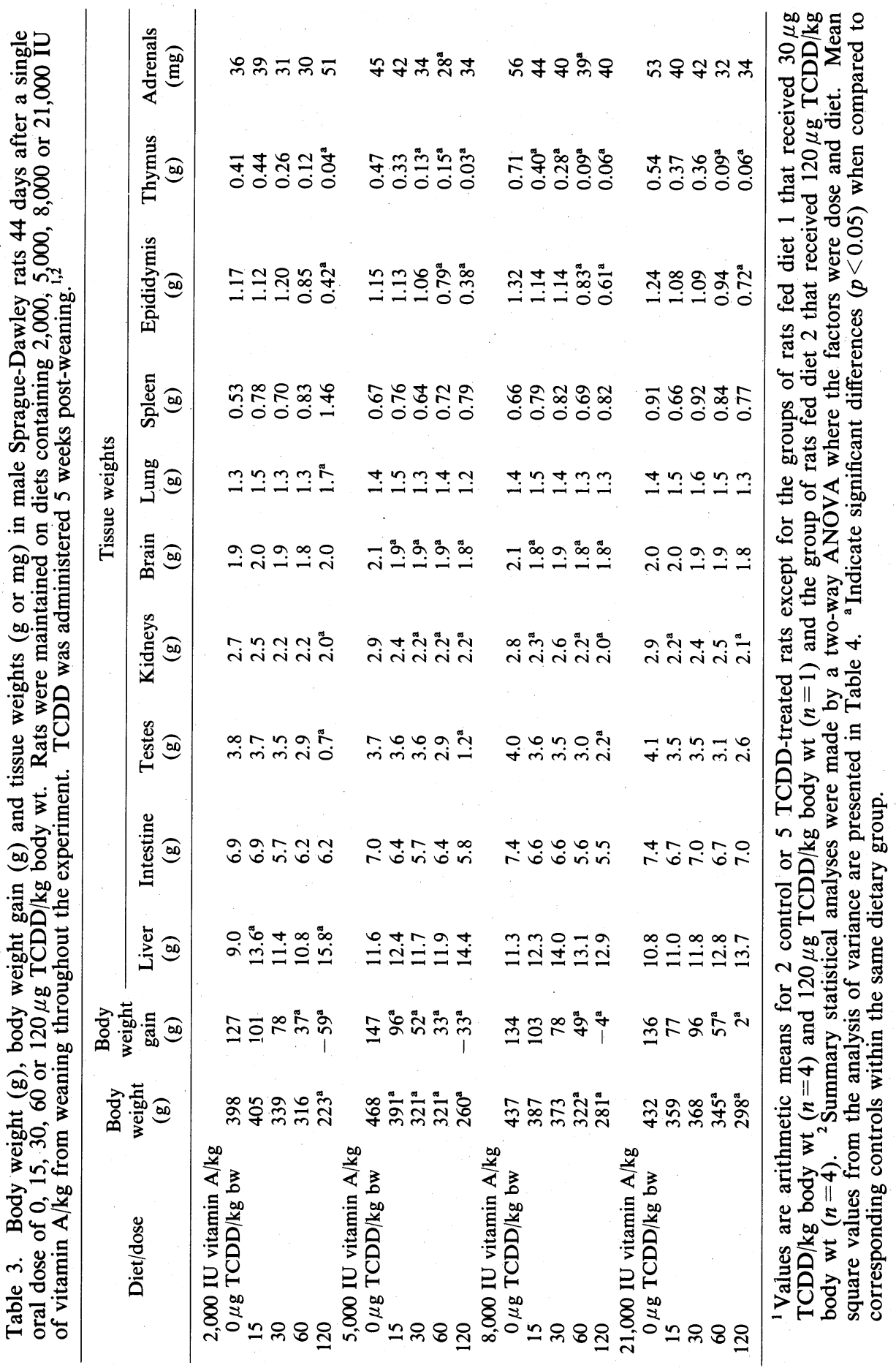




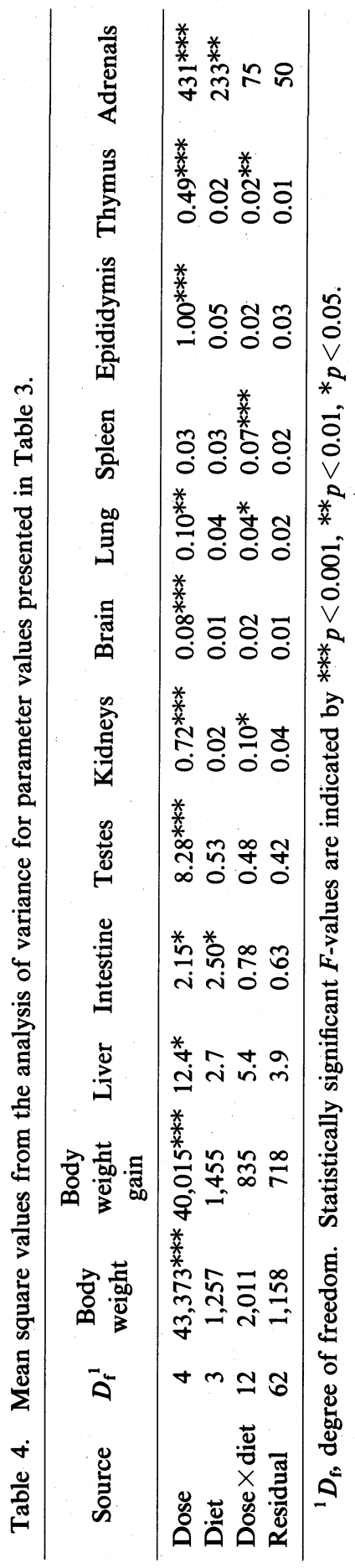

Vol. 37, No. 3, 1991 


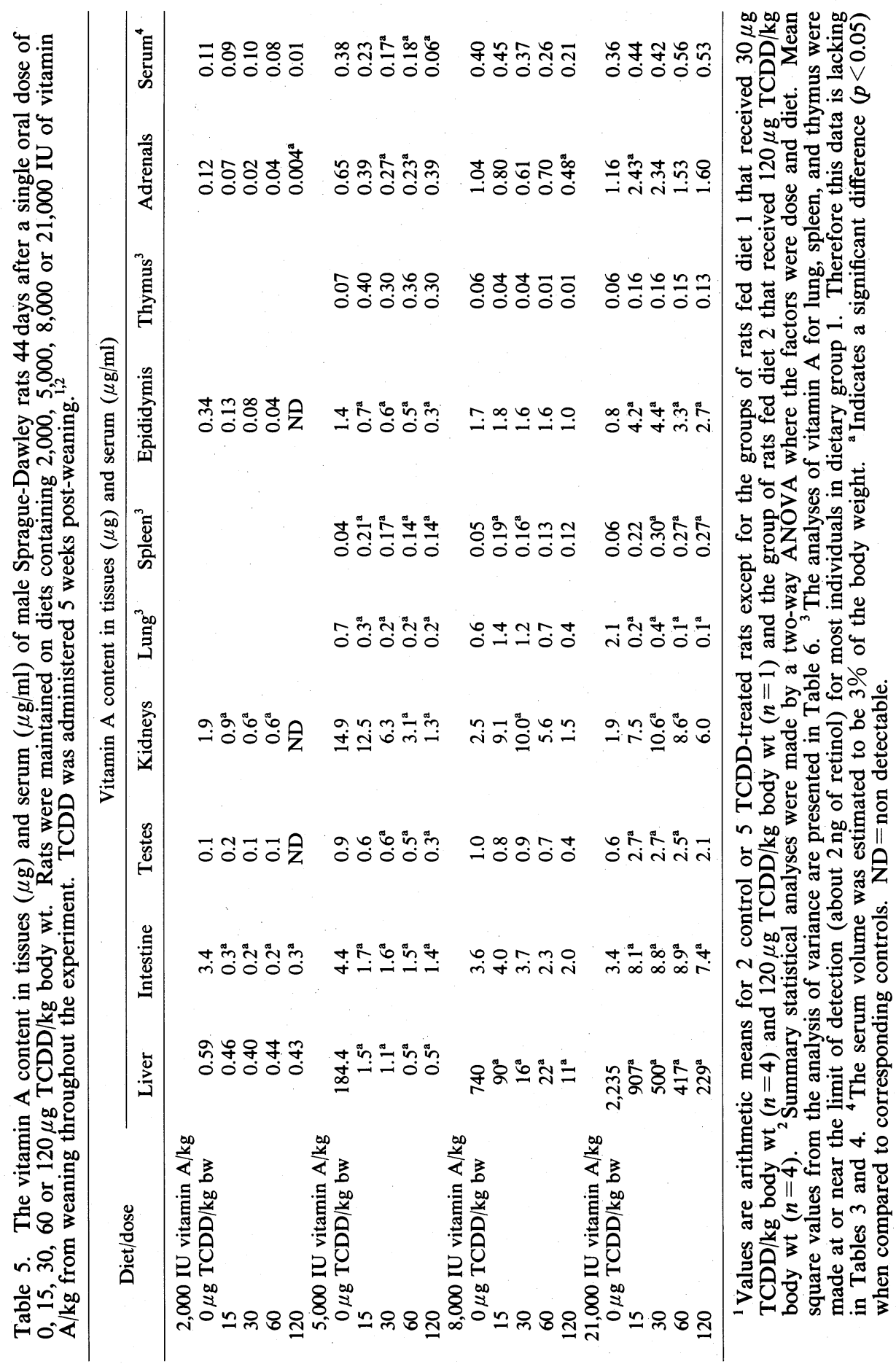




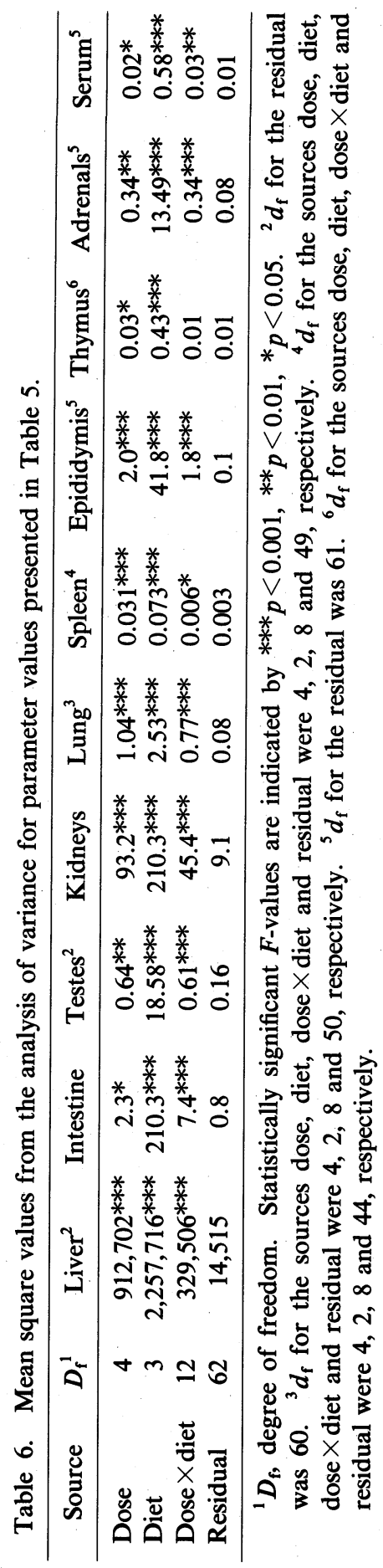

Vol. 37, No. 3, 1991 
content in dietary groups 1, 2, and 3, but increased it in group 4 (Tables 5 and 6). Testes and epididymis of control animals contained about $1 \mu \mathrm{g}$ vitamin $\mathrm{A}$ in all but dietary group 1 , in which lower levels were noted (Table 5). In dietary group 1, TCDD-exposure resulted in decreasing levels of vitamin A in epididymis, whereas no effect was observed in testes (Table 5). Both tissues showed decreasing levels of vitamin A as a result of TCDD-treatment in dietary group 2, while no effect and an increase, respectively, was observed in dietary groups 3 and 4; the higher the dose of TCDD the less pronounced the increase (Table 5).

Control levels of vitamin $\mathrm{A}$ in the kidneys were similar in all but dietary group 2, where considerably more vitamin A was found (Table 5). TCDD-treatment decreased the renal vitamin A content in dietary groups 1 and 2, but increased it above control levels in dietary groups 3 and 4 (Table 5). The TCDD-induced increase in renal vitamin A became less pronounced with the dose both in dietary groups 3 and 4 (Table 5).

Increasing dietary vitamin A intake resulted in increased vitamin A content of control lungs and adrenals but had no effect on the vitamin A content in spleen and thymus of control animals (Table 5). TCDD-treatment decreased the vitamin A content in the lung of rats in dietary groups 2 and 4, while no consistent effect was observed in dietary group 3 (Table 5). The spleen, in contrast, showed increased vitamin A content as a consequence of TCDD-injection in all three dietary groups (Table 5). Thymic vitamin A was increased in TCDD-exposed rats fed diets 2 and 4 , while no effect was present in dietary group 3 (Table 5). Decreasing adrenal vitamin A was observed in TCDD-treated animals fed diets 1, 2, and 3, while animals fed diet 4 showed increased adrenal vitamin $\mathrm{A}$, more so with the lower doses than with the higher (Table 5).

Serum vitamin A was comparable in control rats fed diets 2, 3, and 4, whereas about 70\% lower serum values were noticed for animals fed diet 1 (Table 5). TCDD-exposure resulted in decreasing serum vitamin A levels in rats from dietary groups 1,2, and 3, while a tendency towards increasing serum vitamin A was observed in dietary group 4 (Table 5).

\section{DISCUSSION}

The survival was unexpectedly high in the present study as compared to the previously published i.p. $\mathrm{LD}_{50}$-value of $60 \mu \mathrm{g} \mathrm{TCDD} / \mathrm{kg}$ body wt in adult male Sprague-Dawley rats (24). $\mathrm{LD}_{50}$-values well above $120 \mu \mathrm{g} / \mathrm{kg}$ body wt, however, have been reported for adult Fisher 334N, CD, and Han/Wistar rats given TCDD orally in corn oil $(25,26)$. Due to the low number of dead animals in this study it was not possible to calculate $\mathrm{LD}_{50}$-values for TCDD in any dietary group. The present data, however, suggest that a lower dose of TCDD will be needed to cause death in animals fed a diet containing 5,000 IU of vitamin $\mathrm{A} / \mathrm{kg}$, or less. The data also suggest that the $\mathrm{LD}_{50}$-value for animals receiving 2,000 IU of vitamin $\mathrm{A} / \mathrm{kg}$ diet is in the range $60-120 \mu \mathrm{g} \mathrm{TCDD} / \mathrm{kg}$ body wt, and above $120 \mu \mathrm{g} \mathrm{TCDD} / \mathrm{kg}$ body wt 
for animals that receive $5,000 \mathrm{IU}$ of vitamin $\mathrm{A} / \mathrm{kg}$ diet, or more. Thus, it seems that low dietary intake of vitamin A impairs the ability to tolerate the lethal effect of TCDD, and/or at least decreases the survival time.

A factor other than route of administration, vehicle and strain of rat used, which may contribute to the obtained lethality, is the use of a diet based on casein. There are several studies suggesting that ordinary cereal-based animal feed may increase the toxic effect, using preneoplastic changes in the liver as end-point, as compared to casein-based diets (27-30). The reason for these differences is not clear at present, but it cannot be excluded that the use of a purified diet in this study may have contributed to the low mortality rate observed.

Decreased body weight gain is a major symptom of both TCDD-exposure (17) and dietary vitamin $\mathrm{A}$ deficiency $(18,19)$, thus it was of interest to compare changes in tissue-to-body weight ratios obtained in this study, with changes observed in cases of non-toxic growth reduction (31-33) and/or dietary vitamin A deficiency (34). Based on such comparisons, it appears that the observed increases in liver-, kidney-, and spleen-to-body weight ratios (data from Table 3) are separate both from growth reduction per se as well as from vitamin A deficiency, while the increase in brain-to-body weight ratio seen in TCDD-exposed animals (data from Table 3) most likely is secondary to the reduced body weight gain. It cannot be deduced from data in this (Table 3) and other studies (31-34) whether the reduced testes-, epidymidis-, and thymus-to-body weight ratios and the increased lung- and intestine-to-body weight ratios are primary effects of TCDD-exposure, vitamin A deficiency, and/or of both.

With the dietary regimens used in the present study it was possible to obtain healthy animals of the same age with a vitamin A status that varied within a physiological range. Within the 5 pre-treatment weeks, diet 1 produced moderately vitamin A-deficient animals as judged by normal body weight gain, almost depleted hepatic stores of vitamin $A$, increased renal vitamin $A$, and normal serum vitamin A (Table 1). At the end of the study, control animals fed diet 1 were depleted of hepatic vitamin A, serum vitamin A was below normal, and renal vitamin A was low as compared to 44 days earlier (Table 5). However, body weight gain and relative tissue weights were not different from other dietary groups (Table 3). Diet 2 produced control animals which were marginally vitamin A deficient throughout the study. Rats in this group were able to maintain both the hepatic and serum vitamin A levels (Tables 1 and 5). Renal vitamin A, which was high at the time of treatment, became even higher and approached a value comparable that found in pre-treatment control rats fed diet 1 at the end of the study (Tables 1 and 5). Control animals fed diets 3 and 4 were able to increase the hepatic vitamin A content and to maintain the renal and serum vitamin A levels at similarly low levels throughout the study (Tables 1 and 5). Vitamin A contents in other extrahepatic tissues of control animals remained constant throughout the study (Tables 1 and 5).

Due to the fact that TCDD-reduced food intake is dose-dependent (17), it is unfortunate that no attempts were made to measure food consumption in this 
study. However, previous studies have shown that the TCDD-induced reduction of hepatic vitamin A cannot be fully explained by reduced food intake $(9,10,35,36)$.

The liver plays a central role in the turnover, metabolism and storage of vitamin $\mathbf{A}$ in the body. The parenchymal cells, which constitute the main part of the liver, play a major role in the uptake of vitamin A from serum, while stellate cells are responsible for the main part of hepatic vitamin A storage (14-16). It is known from previous studies that TCDD reduces the hepatic accumulation of ingested vitamin $A(3)$ and increases its mobilization from liver reserves (5). The decrease mainly concerns the storage form of vitamin A, i.e., the retinylesters (2), which are reduced both in liver parenchymal cells and stellate cells (13). It is possible, but not very likely, that TCDD-induced reduction in intestinal absorption and/or hepatic internalization of vitamin A can account for the reduction in hepatic vitamin A content (37). In the present study, exposure to TCDD resulted in a marked decrease in the hepatic vitamin A content as compared to the control level, both at the time of exposure and at termination in all but dietary group 1 (Tables 1 and 5). Increasing the doses of TCDD was required in order to deplete hepatic stores of vitamin $A$ in dietary groups 2, 3, and 4, respectively, while diet 1 in itself depleted liver stores to a minimum level (Table 5). The "undepletable" amount of hepatic vitamin $\mathbf{A}$ in dietary group 3 was higher than in dietary groups 1 and 2, and more hepatic vitamin A (absolute amount) was depleted with the same dose of TCDD in rats with high as opposed to low liver reserves (Table 5). Since the amount of vitamin $\mathrm{A}$ in stellate cells increases markedly as a result of increased dietary vitamin A intake, while the amount of vitamin A in parenchymal cells remains more or less the same (14), our data support the notion that TCDD primarily damages the vitamin A-storing capacity of the stellate cells. A decrease in the vitamin A content in stellate cells would occur if TCDD inhibits the transfer of vitamin A from the parenchymal cell into the stellate cell and/or triggers the release of vitamin A from the stellate cell into the circulation. Further studies are needed to explore these possibilities. Damage could also be a consequence of cytotoxicity and/or transformation of the stellate cell into a cell lacking the capacity to house vitamin A. Although the liver is a well-known target organ for TCDD (17), its effect on the number, morphology and/or function of stellate cells has not been investigated. A related but less toxic and persistent compound, 3,3',4,4'tetrachlorobiphenyl, however, produces minimal morphological changes in the stellate cells at doses where alterations in hepatic vitamin A content and parenchymal cell morphology are observed (38).

The comparatively high levels of vitamin $A$ in serum and several peripheral tissues observed in rats with concurrent high vitamin A status and high TCDDexposure (Table 5), are likely to occur because vitamin A overflows the hepatic storage capacity in cases of severe liver damage. A linear dose-response relationship for hepatic vitamin A reduction was present in dietary group 4 only (Table 5). Since inhibited hepatic vitamin A accumulation tends to last longer in animals receiving a high, compared with a low, dose of $\operatorname{TCDD}(11)$, one may speculate that 
a linear effect over the whole dose-range might also have developed in dietary groups 2 and 3, had the study lasted long enough to allow animals from all groups to regain their full capacity to store vitamin A.

Unaffected, increased, and decreased levels of serum vitamin A have been recorded in rats of variable vitamin A status exposed to single doses of TCDD. Increases in serum vitamin $A$ levels were found in adult $(1,3,6)$ and weanling-aged (11) vitamin A sufficient rats, while no effect or decreases were found in deficient or marginally vitamin A sufficient adult rats $(2,5,27)$. These observations are in agreement with results in the present study (Table 5). In general, the response, which among other things seems to depend on dose, time after treatment, and hepatic vitamin A reserves, was small and variable. Only animals with depleted liver reserves showed serum levels of vitamin A characteristic of vitamin A deficiency (Table 5). The most pronounced increase in serum vitamin A was observed in rats receiving diet 4 and the two high doses of TCDD (Table 5). This elevation would indicate that severe liver damage contributes to the increased level of circulating vitamin A. It is known that plasma levels of retinol are regulated within narrow homeostatic limits independent of alterations in liver reserves over a broad range. Only when the reserves are critically depleted or excessively saturated is there a change in plasma levels. Control mechanisms for maintaining the homeostatic level of circulating retinol are not known in detail but seem to involve both the generation of extrahepatic regulatory signals during the uptake and/or utilization of retinol in target tissues $(39,40)$, the hepatic synthesis and the secretion of the retinol-binding protein (41). The lack of an immediate and pronounced effect of TCDD on the serum vitamin A level in this and previous studies makes it unlikely that TCDD has a direct effect on the proposed homeostatic control of the vitamin A blood level.

The effect of TCDD on renal vitamin A differed markedly depending on the dose of TCDD and on the vitamin A status of the animal (Table 5). A pronounced increase in renal levels of vitamin A following TCDD treatment was observed in vitamin A sufficient rats, despite the fact that these animals still had considerable hepatic stores of vitamin $\mathbf{A}$, and continued to eat the same vitamin A-containing diet (Table 5). In contrast, decreasing renal vitamin A levels were observed in rats which, due to poor vitamin A supplementation and/or TCDD-exposure, had marginal or depleted liver reserves (Table 5). The accumulation of vitamin $A$ in the kidney was maximal at doses of $15-30 \mu \mathrm{g}$ TCDD $/ \mathrm{kg}$ body weight, while decreasing levels were found at higher doses (Table 5). These data are in agreement with those of Jurek et al. (42), who also demonstrated that both exposure to TCDD and intake of a vitamin A-free diet induce a concurrent increase in the renal formation of retinylesters. Taken together, these data suggest that TCDD induces a condition that mimics vitamin A deficiency with respect to renal vitamin A accumulation (42-44). Since the kidney is one of the few organs more or less resistant to the toxicity of TCDD (17), it is unlikely that the response obtained is due to TCDD-induced damage of the kidney. The present and previous 
$(1-3,5-8,12,42)$ results, rather, suggest that TCDD treatment disturbs the mechanism for monitoring changes in liver reserves and/or exogenous supply of vitamin $\mathrm{A}$, which has been proposed to be localized to the kidney $(43,44)$.

Vitamin A contents in the intestine, testes, lung, spleen, epididymis, thymus, and adrenal glands of control rats receiving diets 2,3 , and 4 were roughly comparable for each individual organ (Table 5). This would suggest that peripheral tissue contents of vitamin A are maintained fairly constant over a broad range of liver reserves and dietary vitamin $A$ intakes. In contrast, inadequate vitamin A intake (diet 1) results in markedly lower peripheral tissue levels (Table 5). The effect of TCDD on peripheral tissue levels of vitamin A in the rat varied markedly with the dietary vitamin A status of the animals. Rats receiving diets containing low and intermediate levels of vitamin A generally showed decreased or unaffected vitamin A contents in peripheral tissues as a result of TCDD exposure, while tissues of rats fed excess amounts of vitamin A generally showed increased vitamin A contents (Table 5). Decreases in tissue vitamin A levels induced by TCDD may be the result of decreased storage (similar to the effect in the liver), or increased utilization of vitamin $\mathrm{A}$, which is not compensated for by increased vitamin A distribution to that particular tissue. The increased tissue levels of vitamin $A$, observed in TCDD exposed animals having large liver reserves and continued excessive intake of vitamin $A$, may be a consequence of increased amounts of circulating vitamin A. This vitamin may either be preferentially stored in extrahepatic tissues or retained there because it cannot be eliminated; possibly because the system for "non-functional" metabolism of vitamin A is overloaded.

To summarize, data presented herein show that dietary vitamin A provides limited protection against some typical TCDD-related toxic effects. Exposure to TCDD has a pronounced effect on tissue vitamin A contents. The effect differs between tissues and is dependent upon the dose of TCDD and the vitamin A status of the animal. Generally, exposure to TCDD results in the reduction of vitamin A in most organs; most likely because the capacity for vitamin A storage is diminished. The kidney is an exception, because it accumulates vitamin A either in response to TCDD itself or to the altered vitamin A status which it induces. The pronounced effect of TCDD on tissue vitamin A contents, which differs between tissues, is markedly dependent upon the vitamin A status of the animal. The tissue level of vitamin A required to maintain proper tissue histology and function in vivo is not known for any target organ. Thus, conclusions as to whether the observed changes of tissue vitamin A levels are responsible for the spectrum of morphological changes observed after TCDD exposure cannot be drawn, based on data presented in this study. However, it is likely that decreasing levels of vitamin A in target tissues adversely affects the functioning of these organs. On the other hand, increasing levels of vitamin A are more likely to be harmless, at least in tissues capable of storing excess vitamin A.

The authors thank Sabine Hellman, Marina Nyborg and Lola Chune for animal care 
and technical assistance.

\section{REFERENCES}

1) Bank, P. A., Salyers, K. L., and Zile, M. H. (1989): Effect of tetrachlorodibenzo-pdioxin (TCDD) on the glucuronidation of retinoic acid in the rat. Biochim. Biophys. Acta, 993, 1-6.

2) Brouwer, A., Håkansson, H., Kukler, A., van den Berg, K., and Ahlborg, U. G. (1989): Marked alterations in retinoid homeostasis of Sprague-Dawley rats induced by a single i.p. dose of $10 \mu \mathrm{g} / \mathrm{kg}$ of 2,3,7,8-tetrachlorodibenzo-p-dioxin. Toxicology, 58, 267-283.

3) Hakkansson, H., and Ahlborg, U. G. (1985): The effect of 2,3,7,8-tetrachlorodibenzo-p-dioxin (TCDD) on the uptake, distribution and excretion of a single oral dose of $\left[11,12-{ }^{3} \mathrm{H}\right]$-retinyl acetate and on the vitamin A status in the rat. J. Nutr., 115, 759771.

4) Håkansson, H., and Hanberg, A. (1969): The distribution of $\left[{ }^{14} \mathrm{C}\right]-2,3,7,8$-tetrachlorodibenzo- $p$-dioxin (TCDD) and its effect on the vitamin A content in parenchymal and stellate cells of rat liver. J. Nutr., 119, 573-580.

5) Håkansson, H., Johansson, L., and Ahlborg, U. G. (1988): Effects of 2,3,7,8-tetrachlorodibenzo-p-dioxin (TCDD) on tissue levels of vitamin A and on the distribution and excretion of the endogenous pool of vitamin $A$ in the marginally vitamin $A$ sufficient rat. Chemosphere, 17, 1781-1793.

6) Håkansson, H., Wærn, F., and Ahlborg, U. G. (1987): Effects of 2,3,7,8-tetrachlorodibenzo-p-dioxin (TCDD) in the lactating rat on maternal and neonatal vitamin $A$ status. J. Nutr., 117, 580-586.

7) Pohjanvirta, R., Håkansson, H., Juvonen, R., and Toumisto, J. (1990): Effects of TCDD on vitamin A status and liver microsomal enzyme activities in a TCDDsusceptible and a TCDD-resistant rat strain. Fd. Chem. Toxicol., 28, 197-203.

8) Thunberg, T. (1983): The effect of TCDD on vitamin A in normal and in vitamin A-deficient rats. Chemosphere, 12, 577-580.

9) Thunberg, T., Ahlborg, U. G., and Johansson, H. (1979): Vitamin A status in the rat after a single oral dose of 2,3,7,8-tetrachlorodibenzo-p-dioxin. Arch. Toxicol., 42, 265274.

10) Thunberg, T., Ahlborg, U. G., Håkansson, H., Krantz, C., and Monier, M. (1980): Effect of 2,3,7,8-tetrachlorodibenzo-p-dioxin on the hepatic storage of retinol in rats with different dietary supplies of vitamin A (retinol). Arch. Toxicol., 45, 273-285.

11) Håkansson, H., Johansson, L., Manzoor, E., and Ahlborg, U. G. (1991): Effects of 2,3,7,8-tetrachlorodibenzo-p-dioxin (TCDD) on the vitamin A status of Hartley guinea pigs, Sprague-Dawley rats, C57B1/6 mice, DBA/2 mice, and Golden Syrian hamsters. J. Nutr. Sci. Vitaminol., 37, 117-138.

12) Thunberg, T. (1984): Effect of TCDD on vitamin A and its relation to TCDD-toxicity. in Biological Mechanism of Dioxin Action, ed. by Poland, A., and Kimbrough, R. D., Banbury Rep. 18, Cold Spring Harbor Laboratory, NY, pp. 333-344.

13) Hanberg, A., Trossvik, C., and Håkansson, H. (1991): TCDD-induced effects on retinoids in parenchymal and stellate cells in guinea pigs, rats, mice and hamsters. Abstract, which will be presented at the 11th International Symposium on Chlorinated 
Dioxins and Related Compounds in Chapel Hill, NC, U.S.A., September 23-27, 1991.

14) Batres, R. O., and Olson, J. A. (1987): Relative amount and ester composition of vitamin $A$ in rat hepatocytes as a function of the method of cell preparation and of total liver stores. J. Nutr., 117, 77-82.

15) Blomhoff, R., Green, M. R., Berg, T., and Norum, K. R. (1990): Transport and storage of vitamin A. Science, 250, 399-404.

16) Hendriks, H. F. J., Brouwer, A., and Knook, D. L. (1987): The role of hepatic fat-storing (stellate) cells in retinoid metabolism. Hepatology, 7, 1368-1371.

17) WHO (1989): Environmental Health Criteria 88: Polychlorinated dibenzo-paradioxins and dibenzofurans. World Health Organization, Geneva.

18) Corey, J. E., and Hayes, K. C. (1972): Cerebrospinal fluid pressure, growth and hematology in relation to retinol status of the rat in acute vitamin A deficiency. $J$. Nutr., 102, 1585-1594.

19) Hayes, K. C. (1971): On the pathophysiology of vitamin A deficiency. Nutr. Rev., 29, 3-6.

20) Wolf, G. (1980): Vitamin A. in Human Nutrition, a Comprehensive Treatise, ed. by Alfin-Slater, R. B., Krischevsky, D., Plenum Press, New York, pp. 97-203.

21) Mason, K. E. (1933): Differences in testes injury and repair after vitamin Adeficiency, vitamin E-deficiency, and inanition. Am. J. Anat., 52, 153-241.

22) Thompson, J. N., Howell, J. Mc. C., and Pitt, G. A. J. (1964): Vitamin A and reproduction in rats. Proc. Roy. Soc. B, 159, 510-535.

23) Sokal, R. R., and Rohlf, F. J. (1981): Biometry. WH Freeman and Company, San Francisco, CA.

24) Beatty, P. W., Vaughn, W. K., and Neal, R. A. (1978): Effect of alteration of rat hepatic mixed-function oxidase (MFO) activity on the toxicity of 2,3,7,8-tetrachlorodibenzo-p-dioxin (TCDD). Toxicol. Appl. Pharmacol., 45, 513-519.

25) Pohjanvirta, R., and Tuomisto, J. (1987): Han/Wistar rats are exceptionally resistant to TCDD. II. Arch. Toxicol., Suppl. 11, 344-347.

26) Walden, R., and Schiller, C. M. (1985): Comparative toxicity of 2,3,7,8-tetrachlorodibenzo-p-dioxin (TCDD) in four (sub)strains of adult male rats. Toxicol. Appl. Pharmacol., 77, 490-495.

27) Flodström, S., Busk, L., Kronevi, T., and Ahlborg, U. G. (1991): Modulation of 2,3,7,8-tetrachlorodibenzo-p-dioxin (TCDD) and phenobarbital-induced promotion of hepatocarcinogenesis in rats by the type of diet and vitamin A deficiency. Fundam. Appl. Toxicol., 16, 375-391.

28) Glauert, H. P., Schwarz, M., and Pitot, H. C. (1986): The phenotypic stability of altered hepatic foci: effect of the short-term withdrawal of phenobarbital and of the long-term feeding of purified diets after the withdrawal of phenobarbital. Carcinogenesis, 7, 117-121.

29) Goldsworthy, T. L., Hamm, T. E., Jr., Rickert, D. E., and Popp, J. A. (1986): The effect of diet on 2,6-dinitrotoluene hepatocarcinogenesis. Carcinogenesis, 7, 19091915.

30) Hendrich, S., Glauert, H. P., and Pitot, H. C. (1986): The phenotypic stability of altered hepatic foci: effects of withdrawal and subsequent readministration of phenobarbital. Carcinogenesis, 7, 2041-2045.

31) Feron, V. J., De Groot, A. P., Spanjers, M. T., and Til, H. P. (1973): An evaluation 
of the criterion "organ weight" under conditions of growth retardation. Fd. Cosmet. Toxicol., 11, 85-94.

32) Oishi, S., Oishi, H., and Hiraga, K. (1979): The effect of food restriction for 4 weeks on common toxicity parameters in male rats. Toxicol. Appl. Pharmacol., 47, 15-22.

33) Schärer, K. (1977): The effect of chronic underfeeding on organ weights of rats. How to interpret organ weight changes in cases of marked growth retardation in toxicity tests? Toxicology, 7, 45-56.

34) Wolbach, S. B., and Howe, P. R. (1925): Tissue changes following deprivation of fat-soluble vitamin A. J. Exp. Med., 42, 753-777.

35) Håkansson, H., Johansson, L., Ahlborg, U. G., Moore, R. W., and Peterson, R. E. (1989): Hepatic vitamin A storage in relation to paired feed restriction and to TCDD-treatment. Chemosphere, 19, 919-920.

36) Håkansson, H., Ahlborg, U. G., Johansson, L., and Poiger, H. (1990): Vitamin A storage in rats subchronically exposed to PCDDs/PCDFs. Chemosphere, 20, 11471150.

37) Håkansson, H. (1988): The effect of 2,3,7,8-tetrachlorodibenzo-p-dioxin on the fate of vitamin A in rodents. Thesis at Karolinska Institutet, Stockholm, Sweden.

38) Durham, S. K., and Brouwer, A. (1989): 3,4,3', $4^{\prime}$-Tetrachlorobiphenyl-induced effects in the rat liver. I. Serum and hepatic retinoid reduction and morphologic changes. Toxicol. Pathol., 17, 536-544.

39) Underwood; B. A., Loerch, J. D., and Lewis, K. C. (1979): Effects of dietary vitamin A deficiency, retinoic acid and protein quantity and quality on serially obtained plasma and liver levels of vitamin A in rats. J. Nutr., 109, 796-806.

40) Kielson, B., Underwood, B. A., and Loerch, J. D. (1979): Effects of retinoic acid on the mobilization of vitamin A from the liver in rats. J. Nutr., 109, 787-795.

41) Goodman, D. S. (1984): Plasma retinol-binding protein. in The Retinoids, ed. by Sporn, M. B., Roberts, A. B., and Goodman, D. S., Academic Press, Orlando, U.S.A., Vol. 2, pp. 41-88.

42) Jurek, M. A., Powers, R. H., Gilbert, L. G., and Aust, S. D. (1990): The effect of TCDD on Acyl CoA: retinol acyltransferase activity and vitamin A accumulation in the kidney of male Sprague-Dawley rats. J. Biochem. Toxicol., 5, 155-160.

43) High, E. G. (1954): Studies on the absorption, deposition and depletion of vitamin A in the rat. Arch. Biochem. Biophys., 49, 19-29.

44) Morita, A., and Nakano, K. (1982): Change in vitamin A content in tissues of rats fed on a vitamin A-free diet. J. Nutr. Sci. Vitaminol., 28, 343-350. 